\title{
“El tigre y la paloma": Una entrevista con Brooklyn Rivera
}

\section{Laura Hobson de Herlihy}

Brooklyn Rivera es un líder miskito desde hace más de veinticinco años, y no hay duda que tiene un carisma muy fuerte. ¿Pero, hasta dónde llegará la simpatía que despierta entre su pueblo miskito?

Este dirigente miskito vino al hotel Las Mercedes, en Managua, para concederme una entrevista. En ella hablé con él únicamente en miskito. Toda la gente miskita me había dicho que Brooklyn habla esta lengua muy correctamente. Yo soy norteamericana y todavía estoy aprendiendo este idioma, por eso tenía miedo de hablar con él en miskito. Tenía palpitaciones. Pero no hubo problemas, pues, aunque yo no sabía algunas palabras de este idioma, él me las aclaró. A Brooklyn no le gusta introducir palabras del inglés y del español en el miskito. Él dice que cuando se usan palabras del inglés y del español, las otras etnias (los creoles y los de habla hispana) oyen y se dan cuenta de qué estamos hablando. Me divirtió mucho oír estas enseñanzas suyas.

Después, al lado de la piscina del hotel Las Mercedes, me contó su historia. Me dijo que había nacido en Li Dakwra. Es el hijo menor de su madre y su signo es Libra. Cuando era niño vivió en Sandy Bay Tara y en Wawa y lo criaron su mamá y su abuela. En su casa no había hombre y no conoció a su papá hasta que tuvo dieciséis años. Lo conoció en Managua, porque él vivía ahí cuando llegó a esta ciudad para estudiar. Brooklyn dice que él salió a su abuela, que era una líder fuerte. El carácter de su abuela era como el de un tigre, pero su mamá era más tranquila, como una paloma.

Me confesó que piensa que esas características, de tigre y de paloma, él las reúne porque las recibió de su madre y de su abuela. Desde Sandy Bay, pasando por Costa Rica y Bilwi, hasta Managua, esas dos caracteristicas, tigre y paloma, le ayudaron a convertirse en el líder máximo de los miskitos.

El cree que aportar a la lucha indígena es la cosa más importante en su vida entera. Antes de convertirse en líder máximo participó en la revolución, después en la guerra, luego apoyó la autonomía y fundó la organización Yátama. Dice que hasta la fecha está luchando siempre por la causa indígena. Piensa que sus logros más grandes hasta ahora son: el trabajo de delimitación de los territorios y el renacimiento del Sihkru Tara.
Para preparar la entrevista, le pregunté a la gente de Bilwi qué pregunta le harían a Brooklyn si tuvieran la oportunidad de hacerla. A las mujeres, a los jovenes de ambos sexos, a Blas Coleman, a las autoridades y a ex combatientes, les hice también la misma pregunta. De tal manera que en la entrevista le formulé las preguntas que ellos me plantearon. Léanlas a continuación, junto con las respuestas de Brooklyn.

(L) La gente dice que usted usa mucha magia para protegerse, ¿por qué la usa?

(B) Si la gente habla es posible que haya algo. Yo, como miskito, lo que los miskitos creen, las cosas que hacen, yo las respeto, creo en ellas y trato de practicarlas. Por eso puedo tener cosas en mi cuerpo, para protegerme, para rechazar, para ser aceptado por todos, y así... lo que pueda haber.

\section{(L) ¿Que tipo de magia le gusta más?}

(B) Bueno, yo creo que hay peligros. Enfrente de nosotros hay odio, gente en contra de uno y con malos pensamientos para dañarnos. De esa clase de cosas, pues, tenemos que protegernos.

(L) ¿Qué le contesta a los niños cuando preguntan por qué hizo la guerra.

(B) Bueno, la guerra no la buscamos nosotros. Yo no quería hacer la guerra. Por eso me quedé en Nicaragua hasta el fin; y comencé a separarme de Fagoth por la guerra, porque él hablaba de la guerra y yo le dije no a la guerra. Eso quiere decir que yo no busqué la guerra, yo no apoyé la guerra. Sin embargo, yo también entré en la guerra, porque son tiempos en que no hay otro camino.

Si uno piensa en el pueblo, entonces había que entrar en la guerra. Tenía que participar. Yo no quería dejar Nicaragua, pero los sandinistas me obligaron a irme. Cuando me fui para Honduras, también hice lo posible para que nuestros miskitos allá no entraran en guerra. Pero yo no tenía salida, no tenía poder para detener la guerra. Cuando me fui para Costa Rica me di cuenta que estaba solo y, sin embargo, la gente tenía esperanzas de que yo hiciera algo. Por eso estuve obligado a meter mi mano en la guerra. 
Entonces es de esa forma que entré a la guerra. Pero lo digo otra vez: yo no provoqué la guerra. Pienso que fueron los sandinistas quienes provocaron la guerra. Y nosotros no tuvimos otro remedio, teníamos que pelear. Teníamos que pelear para estar vivos.

Y si me decís ahora... Bueno, yo no me arrepiento de haber hecho la guerra. Lamento que murió mucha gente, se derramó sangre; pero yo lo hice cuando defendía al pueblo. Así tenía que ser. Con eso no quiero decir que vamos a entrar otra vez en una cosa así. Porque el que conoce la guerra sabe que no es una buena cosa.

\section{(L) ¿Por qué se unió a Daniel?}

(B) No nos unimos, de ninguna manera. Tenemos con Daniel un acuerdo, en cuanto a la política, a propósito de los derechos indígenas, para tener alguna oportunidad, para lograr oportunidades. Los pobres y los indígenas necesitan oportunidades para fortalecerse, necesitan oportunidades para ir desarrollando sus derechos, necesitan oportunidades para crecer. En ese sentido, Daniel y el Frente Sandinista nos dan una oportunidad, y tenemos un acuerdo, pero no es una unión.
(L) ¿En qué año se va a retirar? ¿En la elección de 2011?

(B) Vamos a ver cuándo, vamos a ver, eso no puedo decirlo. Uno cuando entra en la política después no puede decir no. No sé qué va a suceder en el 2011, no sé qué va a suceder. Pero el problema de los otros rojos es que no nos respetan, y no nos dan oportunidades. Quieren a los indígenas, a los miskitos, debajo de sus pies, solo oprimiéndonos, utilizándonos. Y nosotros no vamos con eso. Por eso no sé hasta cuando vamos a entendernos, pero nosotros estamos luchando en la política y el que nos permita ir más adelante, pues tenemos que irnos con ése.

(L) ¿Qué piensa de la intención de nombrar un "wihta tara" (gran lider)?

(B) Yo podría decir: "yo soy wihta tara". Pero yo no hablo de esa manera, porque no tiene sentido darse mucha importancia, alabarse mucho. ¿Para qué nombrar nuevas autoridades com el nombre de "whita tara"? Yo pienso que el asunto no es hacer mayores nuestros problemas. Juntarnos para resolverlos, luchar contra la pobreza, luchar por nuestros derechos, eso es lo que hay que hacer. Empoderar al pueblo y no a una persona, fortalecer nuestra lucha.

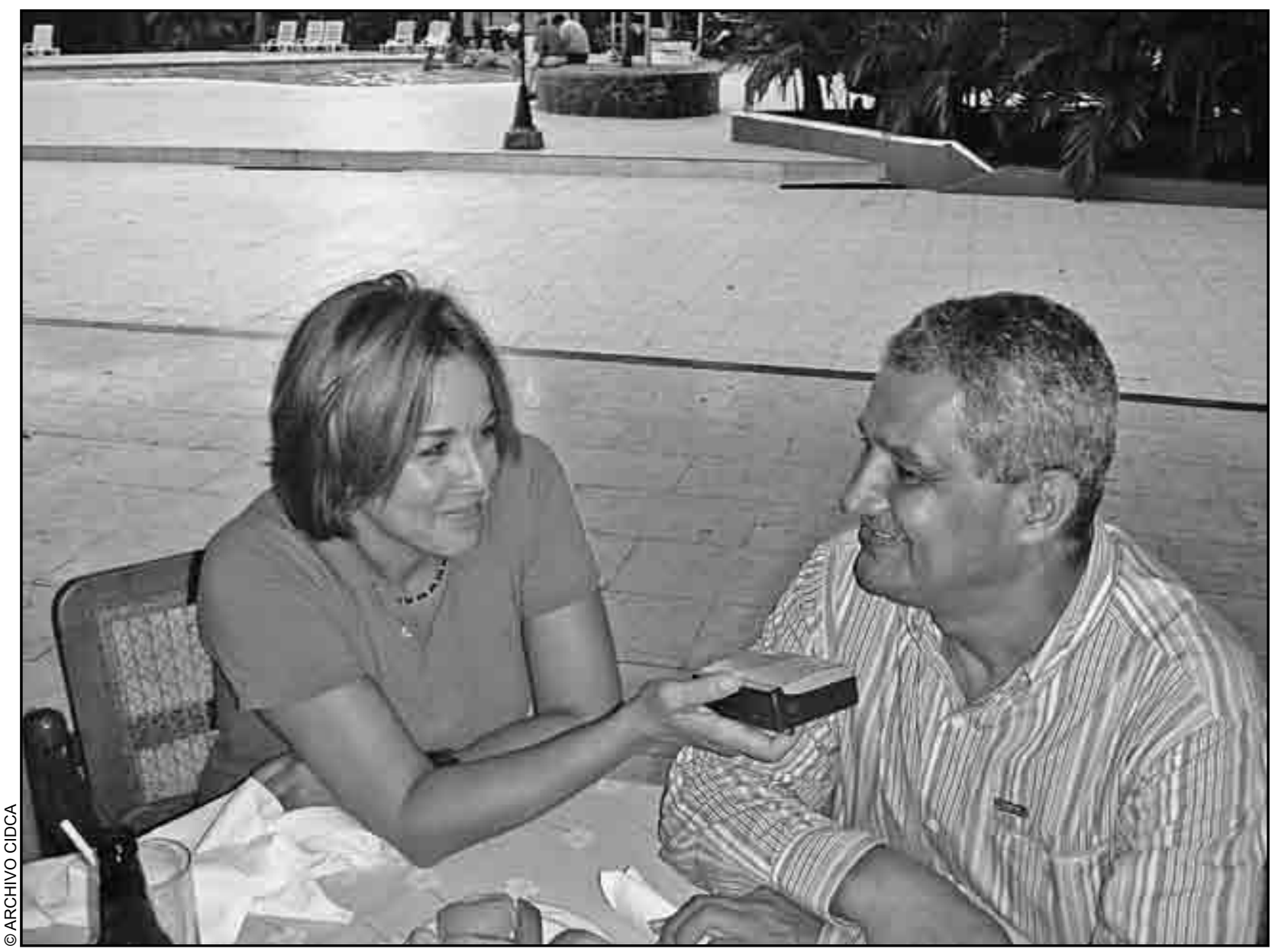

Laura Hobson y Brooklyn Rivera durante la entrevista. 
(L) ¿Cómo es eso de "la lucha por la independencia”?

(B) Bueno el nombre es más grande que la cosa. Suena grande también, pero el trabajo que hacen no lo es. Lo más son palabrerías, puros decires. Yo creo que ellos no entienden muy bien de qué están hablando, ni qué es lo que verdaderamente quieren y, todavía menos, cómo obtenerlo. Ellos hablan de separación, pero no emplean el miskito para decirlo. Hablan en español y dicen "independencia". Esto quiere decir que no entienden en su lengua qué cosa sería independizarse, ni cómo hacerlo.

Yo escuché hablar a un grupo de ancianos y les dije ¿Cómo van a hacer para independizarse? Y me dijeron: "eso está en manos de los líderes". Quiere decir que ni ellos entienden de qué están hablando. Quién sabe qué será. Yo veo que solo confunden a la gente.

Lo que dicen no está en contra de los que hablan español, ni está en contra del gobierno. Y yo veo con extrañeza por qué habrían de estar en contra de Yátama. Yátama es su propia organización, y aunque no la vieran con simpatía es de todos modos una organización miskita, y hay que respetarla. ¿Pero, por qué están contra Yátama? ¿Por qué no están contra los que hablan español ${ }^{1}$ ? ... Extraño. Por eso pienso que son más bien envidias.

Envidias, piensan que Brooklyn la pasa bien, que come, que tiene dinero. No piensan en cómo Brooklyn se mata, batalla, sufre, las luchas que libra para que los miskitos se levanten y salgan adelante. Mi trabajo lo ven los que tienen entendimiento. Yo no ando en esto por mi mismo, ni por un grupo particular.

Ellos dicen: "sólo ustedes comen". Yo les digo: "!Vení, entrá vos también! ¿Por qué no te unís? ¿Que cuando estás enfermo nadie te mira? ¡Entonces vení, vení! Cuando entrés vamos a buscar medicamentos". Nosotros pensamos en todos, en todos, pensamos en nuestros ancianos. Pero lo que hasta ahora no está bien es que no quieren unirse. Y lo triste es que hablan en contra mía. Si estuvieran hablando en contra de los de hablan español estaría bien, si hablaran en contra del gobierno también estaría bien, yo los apoyaría.
Yo no voy con el planteamiento de ellos, porque no le veo sentido, no veo cómo pueda salir algo bueno de eso. Por el momento son ellos los que se equivocan completamente y actualmente no se dan cuenta. Ahora que vienen las elecciones se levantan y hacen bulla, dicen que no hay que votar en las comunidades, pero no votar es votar contra Yátama.

Dicen que no hay que votar, que los miskitos no deben elegir a los de Yátama. Pero si no lo hacen, los que hablan español van a ganar, los partidos de los de habla española. Y nosotros nos hacemos más pobres, más humillados, más débiles. ¿Por qué no meditan sobre estas cosas? Si es para fortalecer a su raza está bien, si luchan por nuestros derechos está bien, si luchan por la unidad está muy bien. Pero de eso no hablan, sólo hablan de la maldad de Broklyn. Dicen que Yátama es malo, y quieren independizarse, y hablan de los norteamericanos, y al final nada sucede. Me entristece, porque quieren destruir nuestra lucha.

Yo pienso que no debería ser así. Todos nosotros debemos unirnos en contra de los que hablan español, debemos unirnos en contra del irrespeto, contra los que no nos respetan. Los de habla española vienen entrando, vienen entrando, vienen entrando, en nuestro territorio. ¿Por qué no se levantan contra esto? Los de habla española se están volviendo demasiados numerosos en Bilwi, y están entrando en las comunidades, y en las tierras. Levantarse contra esto, luchar contra esto, yo eso lo veo bien. Pero, ¿levantarse en contra de nuestros hermanos, de nuestra etnia, tirarles piedras, pelear con ellos? No tiene sentido.

(L) Si Yátama es un partido político, ¿por qué tienen cerco de alambre y la puerta de las oficinas de Yátma cerrada, por qué ese cuidado?

(B) Bueno, Yátama no es un partido político, es una agrupación, aunque engañando a los de habla española digo partido. Yátama lo que es, es una organización del pueblo, como $M A S T A^{2}$, pero lucha dentro de la política y lucha también en las elecciones.

¿Por qué se dice que es partido? Porque participamos en las elecciones. ¿Y por qué participamos en las elecciones?

$1 \quad$ Nota de traducción. En el idioma miskito, los habitantes del lado del Pacifico y Centro de Nicaragua, hablantes de lengua española y en su mayoría provenientes de una mezcla de españoles, negros e indios, son designados con el término genérico de "ispail". Para no confundir al lector hispanohablante hemos traducido "ispail" por "hablante de español" (en otros países se usa el termino "ladino" en un sentido parecido). No es aqui el lugar de ahondar en todo esto, que por supuesto es más complejo.

2 Nota de traducción: MASTA es una organización de los miskitos hondureños que no participa en las elecciones nacionales de Honduras. En Honduras no hay-todavía- regiones autónomas ni gobiernos regionales. 
Bueno, si no participamos, y solo lo hacen los partidos PLC y el Frente, engañando a nuestra gente, ellos van a conseguir los votos. Y los líderes sólo van a ser ellos: los líderes del gobierno, ellos serán el alcalde, el concejal, todos, todos van a ser de esos partidos. Y la mayoría van a ser de habla española, y si hay miskitos van a ser gente de esos partidos políticos. Y nosotros no vamos con eso. Por eso, Yátama participa en las elecciones, pero no es un partido político.

\section{(L) ¿En 2009 qué hizo por la autonomía?}

(B) Bueno, a la autonomía que tenemos ahora la ley no le da mucha facultad. Los partidos tienen más oportunidades, nosotros no podemos hacer mucho desde el Consejo Regional. Nosotros intentamos hacer dos cosas: una es marcar los límites de nuestra tierra, porque dentro de ella debemos desarrollar la autonomía, dentro del territorio; lo segundo es que tenemos que escribir una nueva ley de autonomía. Como Yátama ya tenemos nuestra constitución, revisada. Y eso, cuando sea el momento, lo vamos a presentar en la Asamblea Nacional. Eso hacemos, esas dos cosas empujamos. Delimitamos nuestra frontera y el gobierno indígena va desarrollándose, el gobierno miskito, el gobierno mayangna, van desarrollándose. Eso queremos fortalecer. Y lo otro, cuando llegue la hora, será hacer una nueva ley de autonomía. Porque la que hicieron los sandinistas no es buena, da poder a los de habla española. Los de habla española también votan, los que hablan español también escogen a los líderes. Y nosotros con eso nada logramos. Los partidos políticos, que tienen más poder, ponen a su gente o compran a la gente de los partidos, los usan y disuelven los derechos de los indígenas. Por eso se necesita una nueva ley, una verdadera ley de autonomía.

\section{(L) ¿Quien le cae mejor Zelaya o Micheletti?}

(B) Yo pienso que ambos son de habla española, ambos son ricos, ambos son extraños a nuestra gente. Pero, bueno, como gobierno, como presidente, los miskitos hondureños dicen que nunca conocieron un presidente de ese tipo, bueno. Zelaya los respeta a ellos, los apoya, venía con frecuencia a la Moskitia, Y si ellos lo respetan, yo también respeto a Zelaya. Ellos dicen que no conocen mucho a Micheletti, no lo respetan. Yo tampoco conozco bien a ese Micheletti.

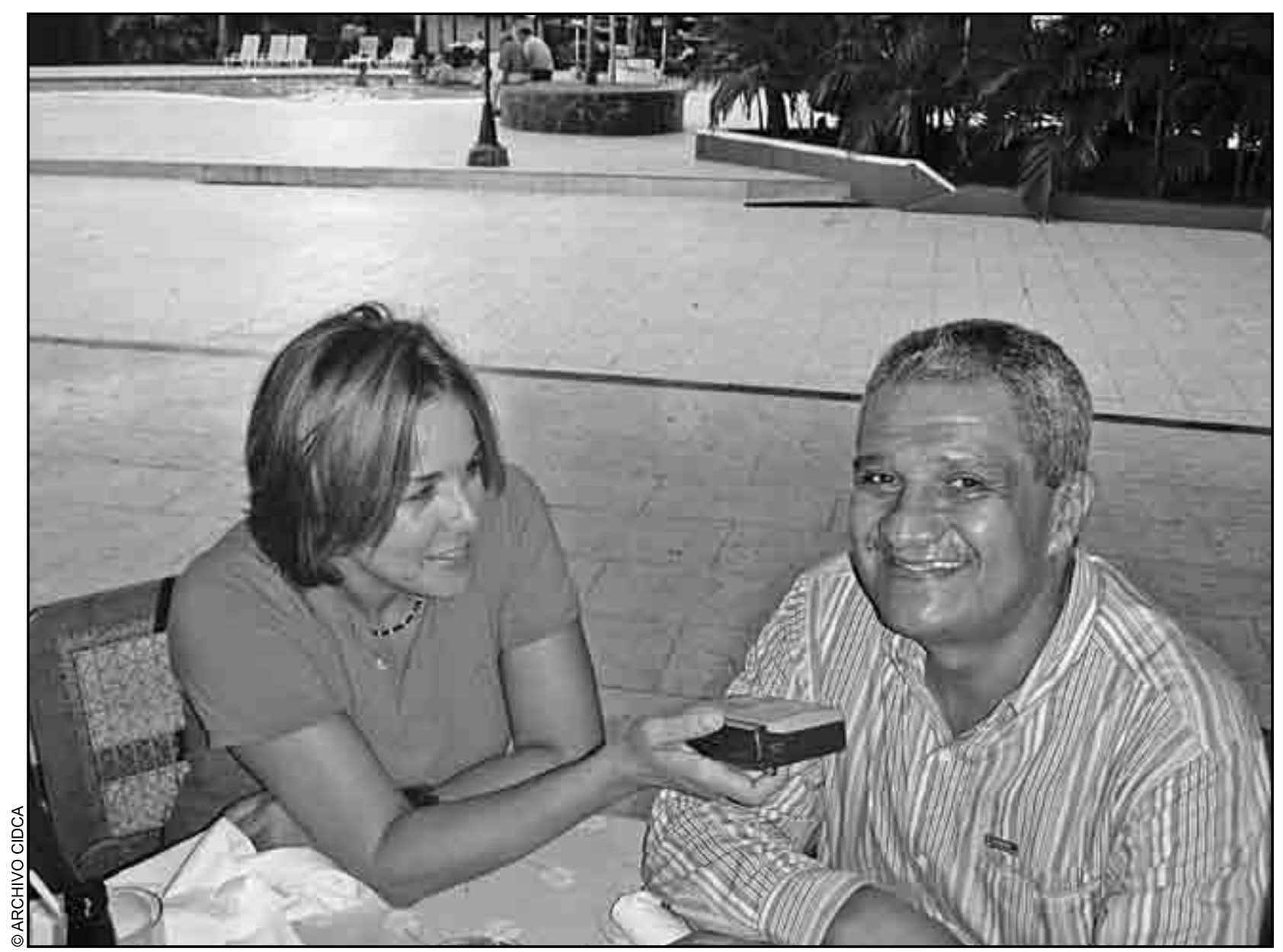

Un momento jocoso durante la entrevista. 
A quien los miskitos hondureños respeten y apoyen yo también lo respeto y apoyo...Los miskitos hondureños apoyan más a Zelaya, MASTA también lo apoya, si.

\section{(L) ¿Cómo estuvo la fiesta del gran Sihkru?}

El gran Sihkru va hacia adelante; con la celebración de este año es la sexta. Lo hacemos todos los años, desde el 2005, uno en Nicaragua y uno en Honduras. Estamos buscando fortalecer nuestra identidad, la identidad miskita, y tambien fortalecemos nuestros derechos, la unidad, la unidad. Esa frontera que pusieron en el rio Coco, nosotros no la vamos a reconocer, hay que quitarla. Se hace por todo eso, pero es a través de la política que vienen muchas cosas más, cuando se hace en unidad. Se puede observar que ellos también ahora están hablando sobre la autonomía, sobre la klauna lâka, en Honduras. Se hablaba de eso sólo en Nicaragua, y ellos estaban temerosos, sin entender. Pero ahora ya hablan, y se dan cuenta que ellos no tienen que limitarse a seguir a los partidos politicos. Todos esos son beneficios. Se tiene que seguir trabajando, hay que seguir celebrando el Sihkru, hacerlo mucho más grande. Hay mucha más gente y los maestros tambien participaron, los maestros de Nicaragua que dan clases. La gente de los partidos, la gente que habla español ven cómo nuestra gente celebra sin vergüenza y con orgullo el Sihkru Tara. Cuando se celebró en el estadio, en ese día del indio, y en el cual los maestros participaron, fue muy hermoso. Me alegré mucho más. No fueron sólamente los jóvenes sino también los maestros, fue una gran cosa. Y nosotros queremos que todas las etnias lo celebren, no sólo en Bilwi, no sólamente en Waspam, en Rosita. Ahora también ya lo celebraron en Rosita. Y llevarlo a Bonanza, a Alamikamba, a Río Grande, a Karawala, a Bluefields, por todos lados. Yo veo que va creciendo el Sihkru. Cada vez hay más personas que entienden, a más y más les gusta y más y más participan y apoyan. Yo me doy cuenta que tenemos que fortalecer este trabajo; con la ayuda de Dios.

\section{(L) ¿La celebración de Sihkru, en qué manera ha} evolucionado del Sihkru original?

Posiblemente, en la celebración actual haya alguna diferencia. En el pasado se hacían las celebraciones más de acuerdo a las tradiciones indígenas. Pero ahora ya se mezclan muchas cosas, se ponen juntas las tradiciones y

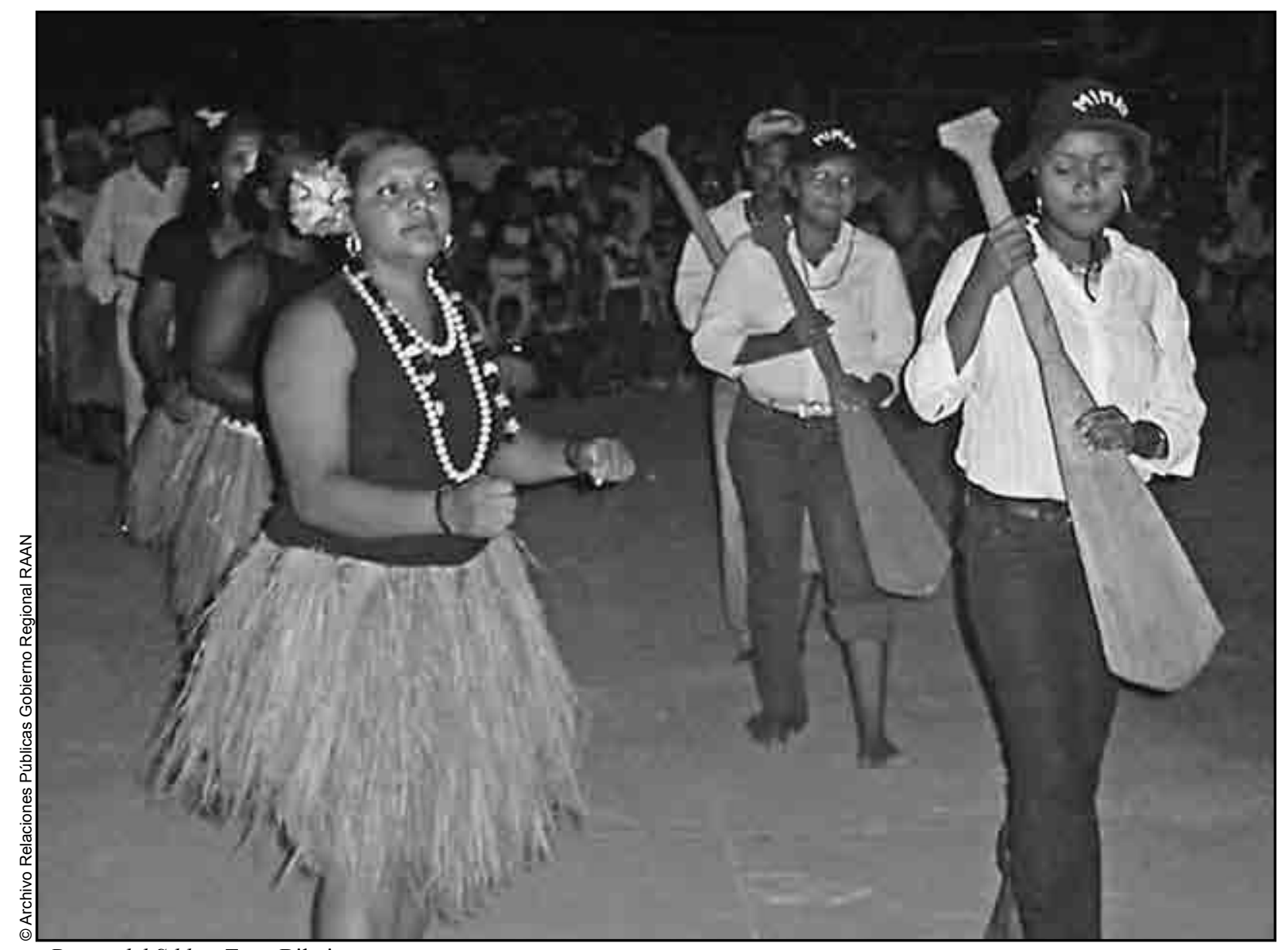

Danza del Sihkru Tara. Bilwi. 
este tiempo. No se pueden separar. De lo tradicional, se intenta hacer lo que se puede en este tiempo, hacerlo de este tiempo, porque vos sabés que sos de este tiempo. No sos de ayer, ahora es hoy, y todo va cambiando. Pero lo significativo es que vos tratás de hacer las cosas de ayer, darles valor, ir enseñando a los niños, a los jóvenes. En el pasado, la celebración se hacía más de acuerdo a las tradiciones indígenas, celebraban más a los muertos. Los ancianos lo hacen de un modo un poco diferente, incluyen otros detalles. Pero ya están participando muchas plañideras, ves los llantos, su costumbre de cómo lloran a sus muertos. Todo eso fue muy bueno, me doy cuenta que se estaría perdiendo si no fuera por eso. Los llantos de los ancianos cuando mueren nuestros parientes, son llantos bellos, pero se están perdiendo, y por eso, en este Sihkru ya se incluyeron un poquito. Entonces, no sólo son danzas, sino que, bueno, los espíritus, los ritos mortuorios, los pensamientos, los estilos, se van incluyendo. Yo creo que es bueno tratar de ir tomando más en cuenta a nuestros ancianos siempre. Quiero decir que hay que prepararse con mucho más tiempo. Yo no sé cuantas cosas más pueden venir desde Honduras en ese sentido. Por eso quiero intentar ir allá otra vez, hablar más, para que se preparen más los ancianos. Si Dios quiere vamos a ir a Kaukira, a investigar más sobre las celebraciones de nuestros antepasados.

\section{(L) ¿Por medio del Sihkru se está haciendo política?}

(B) En todo lo que la gente hace hay política, por eso no puedo decirse que no hay política.

Estos juegos son políticos, y lo que se busca traer al presente es el espíritu de los antepasados, y eso es político. Toda esa variedad de pensamientos, el tipo de comida, la vestimenta y los diferentes juegos son políticos. En todo trabajo que desarrolla una persona hay política, buena o mala.
Entonces, hay política en la celebración de Sihkru, yo no voy a negar eso. Pero no es política de partido, no es política de gobierno. Existe una política del pueblo indígena. Claro que con esto, Yátama puede beneficiarse, porque es una organización. Como organización tiene que recibir beneficios, y tiene derecho a recibir beneficios. Por eso, cuando el pueblo es más fuerte, Yátama también puede volverse más fuerte. Nosotros estamos en contra de un partido y estamos en contra de los que hablan español, los que hablan español no deben fortalecerse, no es nuestro deseo. Tenemos que fortalecer a los miskitos. Por eso, con esta celebración derrotamos a los de habla española, los debilitamos, destruimos las discotecas y los bares que están llenando Bilwi, tenemos que eliminarlos. Tenemos que atraer a la gente a nuestra corriente, a nuestras costumbres. Los de habla española piensan que sólo ellos tienen música, celebraciones, y que la gente los sigue.

Y la nostalgia, con las celebraciones de Sihkru, hay que aumentarla. La gente quiere enraizar sus costumbres, ponerse de pie como miskitos. Y esto no le parece bien a los de habla española; porque la gente se da cuenta que es diferente, que sus costumbres no son las de los de habla hispana, que no necesitan convertirse en personas de habla española. Y esto puede ser un arma contra los de habla española.

Esto también lo enfatizamos allá del otro lado, en Honduras. Porque allá yo veo que se habla mucho en español, hay mucha imitación y miedo a la gente de habla española. Aquí también le tienen miedo a los de habla española. Entonces, el Sihkru debe ser un arma fuerte, para no tener miedo, y para no ser sumisos, sino que hacer respetar nuestra autonomía.

Y si esto es política, bueno, es la política de un pueblo. 